\title{
Reduction of soot emissions in diesel engines due to increased air utilization by new spray hole configurations
}

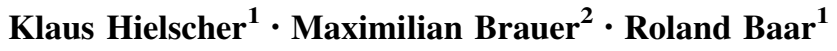

Received: 7 December 2015/Accepted: 12 September 2016/Published online: 20 September 2016

(C) Springer International Publishing Switzerland 2016

\begin{abstract}
With conventional combustion processes there remain unused regions with air between the injection jets. To use these, a 14-hole-nozzle and a nozzle with six smaller and six larger spray hole diameters were developed. Both nozzles show strongly increased soot emissions. The optical analysis shows that the combustion zones of the 14-hole-nozzle overlap and create very rich local combustion zones. Furthermore, the small spray hole diameters reduce the spray momentum and a backflow from the piston bowl which would lead to improved air utilization cannot be created. The small spray holes of the 6+6-nozzle create a spray momentum that is too large to only use the air in the middle of the combustion chamber. At the same time the injection jets restrain the backflow generated by the larger spray holes.
\end{abstract}

Keywords Air utilization - Soot emission - Spray momentum · Wall-jet - Backflow · Number of spray holes · Spray hole diameter

$\begin{array}{ll}\text { Abbreviations } \\ \text { PM } & \text { Particulate matter } \\ \text { AFR } & \text { Air fuel ratio } \\ \text { CA } & \text { Crank angle } \\ \text { CMOS } & \text { Complementary metal-oxide-semiconductor }\end{array}$

Klaus Hielscher

klaus.hielscher@tu-berlin.de

Maximilian Brauer

dr.maximilian.brauer@iav.de

Roland Baar

roland.baar@tu-berlin.de

1 Technical University Berlin, Chair of Internal Combustion Engines, Berlin, Germany

2 IAV GmbH, Development Center Berlin, Berlin, Germany

$\begin{array}{ll}\text { SoL } & \text { Soot luminosity } \\ \mathrm{OH}^{*} & \text { Hydroxyl radical } \\ \text { OH-chem } & \text { OH-chemiluminescence } \\ \text { COHR } & \text { Center of heat release } \\ p_{\text {mi,HP }} & \text { Indicated pressure high pressure cycle } \\ \text { PI } & \text { Pre-injection } \\ \text { MI } & \text { Main-injection } \\ \text { SOE } & \text { Start of injection } \\ \text { ET } & \text { Energizing time } \\ \text { HRR } & \text { Heat release rate } \\ \text { bi } & \text { Indicated fuel consumption high pressure } \\ & \begin{array}{l}\text { cycle } \\ \text { SLM }\end{array} \\ \text { PIV } & \text { Scattered-light method } \\ & \text { Particle image velocimetry }\end{array}$

\section{Introduction}

Ever stricter emission limits have led to the development of diesel injection systems with smaller spray hole diameters and higher injection pressure. Also the number of spray holes has been varied. Conventional combustion processes show unused regions with air between the injection jets at the beginning of combustion. The aim of this study is to utilize those regions for the combustion with the help of new spray hole configurations with a larger number of holes to finally reduce the soot emissions.

\section{Fundamentals}

\subsection{Soot emissions}

Soot is the essential part of the particulate matter (PM) emissions of combustion engines. The main factors 
influencing the soot-formation and oxidation are the air fuel ratio (AFR) and the combustion temperature. The conventional diesel combustion process is largely diffusion controlled. Because of the characteristic of the diesel process, the local AFR and the local combustion temperatures differ widely. Most of the soot formed in the beginning of the combustion will be oxidized at a later stage of the combustion process. The formation of soot occurs with a local lack of air. This process is enhanced at an AFR of 0.5 or below and a temperature of 1500-2500 K. For the soot oxidation, excess air and a temperature above $1800 \mathrm{~K}$ is required [1].

\subsection{Mixture formation}

The spray hole is the last part of the injection system the fuel passes, hence the influence on the mixture formation and combustion is high. The factor with the greatest influence is the spray hole diameter. Decreased diameters lead to smaller mean droplet size because of an improved spray break-up [2]. The air entrainment into the spray jets increases relative to the injected fuel mass and the fuel can evaporate more rapidly [3]. Finally this leads to a lean mixture which generally has a positive effect on the soot emissions. Smaller spray hole diameters reduce the spray momentum and reduce the penetration depth of the liquid as well as the vapor fuel [5]. This has a special significance for passenger car engines because of their relatively small cylinder bores. In these engines, the injected fuel interacts with the wall of the combustion chamber in the form of the piston bowl. The liquid or vapor fuel is deflected on the wall which leads to so called wall-jets which create vortices (Fig. 1). The wall-jets occur in the circumferential direction as well as in radial direction. So with sufficient spray momentum the fuel is reflected by the piston bowl

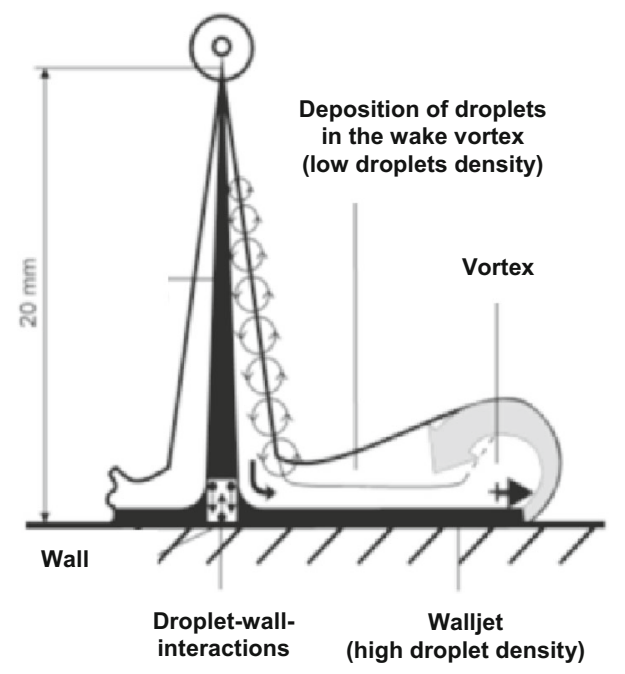

Fig. 1 Jet-wall interaction [4] and flows back to the middle of the combustion chamber which leads to higher air entrainment. The vortices support the transport of fuel back towards the middle of the combustion chamber too [6]. These effects can decrease the soot emissions in low load ranges [6-8]. On the other hand the soot emissions can increase if fuel deposits on the wall [9].

\section{Experimental setup}

\subsection{Single cylinder emission engine}

To evaluate the nozzles in terms of the effective fuel consumption and the soot-emissions they were first measured on a single cylinder emission engine. The combustion process of the engine is based on a $2.2 \mathrm{~L}$ four-cylinder diesel engine from the passenger car sector. The characteristic data of the engine are set out in Table 1. The shape of the piston bowl, the cylinder head and the intake manifold correspond to the original four-cylinder engine.

\subsection{Single cylinder optical engine}

The transparent engine with its extended and slotted piston corresponds to the engine of Bowditch [10]. The piston crown provides an optical access through a quartz window. The diameter of the visible area is $47.8 \mathrm{~mm}$ while the maximum diameter of the piston bowl is $55.4 \mathrm{~mm}$. The shape of the bowl is the same as in the original engine. The upper part of the liner is designed as an exchangeable ring that can be made of aluminum or quartz glass. This requires a correspondingly deep position of the piston rings and results in an enlarged top land which decreases the compression ratio to $\varepsilon=14.9$. Contrary to most transparent engine concepts, this engine provides two conventional compression rings made of steel. The lubrication is ensured by a felt ring below the compression rings that has to be saturated with oil manually.

\subsection{Injection system}

The injection system is a common rail system with a prototype injector. For the emission engine a near-series engine control unit was used while for the special

Table 1 Geometric data of the emission engine

\begin{tabular}{ll}
\hline Stroke & $99 \mathrm{~mm}$ \\
Bore & $83 \mathrm{~mm}$ \\
Cylinder displacement & $536 \mathrm{~cm}^{3}$ \\
Compression ratio & 16.3 \\
\hline
\end{tabular}


requirements of the transparent engine a development control unit IAV $\mathrm{FI}^{2 \mathrm{RE}}$ had to be used. Five injection nozzles with conical spray holes were analyzed. The spray hole configurations are set out in Table 2.

Two nozzles with eight spray holes and a hydraulic flow of 355 and $400 \mathrm{~cm}^{3} / 30 \mathrm{~s}$, respectively, serve as the references. Based on the HF355/8H nozzle the number of holes was increased to 14 which results in decreased spray hole diameters from 120 to $90 \mu \mathrm{m}$. Moreover, a nozzle with 12 spray holes was analyzed where six larger spray holes $(120 \mu \mathrm{m})$ alternate with six smaller $(90 \mu \mathrm{m})$ spray holes. This nozzle, therefore, is called 6+6-nozzle and has a hydraulic flow rate of $400 \mathrm{~cm}^{3} / 30 \mathrm{~s}$. To analyze the effect of a reduced spray hole diameter independent from an increased number of holes, the research includes an 8-holenozzle with a hydraulic flow of $205 \mathrm{~cm}^{3} / 30 \mathrm{~s}$.

\section{Optical measurement techniques}

Various measurement techniques were used on the optical engine. All recordings were made through the quartz window in the piston head using a deflection-mirror, resulting in an integrated view of the combustion over the depth of the combustion chamber. The high speed cameras are Phantom v1610s from Vision Research and work with a CMOS image sensor. The images were synchronized with the crank angle $(\mathrm{CA})$ at an interval of $0.3^{\circ} \mathrm{CA}$. The resolution of the images is $512 \times 512$ pixels.

\subsection{Scattered-light method}

To visualize the liquid phase of the injection jets, the scattered-light method was used. According to the Mietheory, the light is scattered by particles that are large relative to the wavelength of the incident light. During this process the wavelength remains unchanged [11]. Because the intensity distribution of the scattered light shows a maximum towards the incident light [12], the illumination and the observation can take place through the same optical access. The light source was a high performance ring flash 3000-XS, HENSEL-VISIT GmbH. Its light is transmitted

Table 2 Analyzed spray hole configurations

\begin{tabular}{lll}
\hline Hydraulic flow $\left(\mathrm{cm}^{3} / 30 \mathrm{~s}\right)$ & \multicolumn{2}{l}{ Spray hole } \\
\cline { 2 - 3 } & Number $(-)$ & Diameter $(\mu \mathrm{m})$ \\
\hline 355 & 8 & 120 \\
355 & 14 & 90 \\
400 & 8 & 130 \\
400 & $6+6$ & $90 / 120$ \\
205 & 8 & 90 \\
\hline
\end{tabular}

by the mirror into the cylinder. The flash illuminates the combustion chamber for about $3 \mathrm{~ms}$ so the whole injection process could be illuminated by only one flash.

\subsection{Flame emission spectroscopy}

Flame emission spectroscopy was used to analyze the combustion. This technique is based on the electromagnetic radiation emitted during combustion. In this setup the radiation of the soot and the $\mathrm{OH}$-radicals (chemiluminescence) were analyzed. The soot luminosity is caused by the thermal radiation (blackbody radiation) of the glowing carbon particles. Those emit electromagnetic radiation with a continuous wavelength spectrum. The radiation is detectable in the visible wavelength range but also reaches into the ultraviolet and has its maximum intensity in the infrared range [1]. According to Planck's radiation law the blackbody radiation increases with the temperature and the concentration of the soot [13]. So recording the soot luminosity (SoL) is a suitable method to analyze the diffusion combustion.

The chemiluminescence occurs with exothermic chemical reactions. Here energy can be stored temporarily in the molecules by raising them into an excited state. From this unstable state the molecules return to a lower or to their ground electronic state after a short time, and with that they release the energy as electromagnetic radiation with a characteristic wavelength (band spectrum) [14]. One of those molecules that occurs during the combustion is the hydroxyl radical $\left(\mathrm{OH}^{*}\right)$. It is generated during the reaction of formaldehyde to carbon monoxide [15]. So the beginning of the combustion and the premixed flame in general can be detected with the help of the $\mathrm{OH}$-chemiluminescence (OH-chem.) [15]. The emission spectrum of the $\mathrm{OH}-$ chem. has a maximum intensity at about $310 \mathrm{~nm}[15,16]$. Because the SoL reaches into that range as well, the signals may overlap [15]. With strong SoL the signals can no longer be differentiated and analysis of the OH-chem. is not possible.

The SoL and the $\mathrm{OH}$-chem. are recorded simultaneously in this setup. The radiation from the combustion chamber is, therefore, divided to two cameras with a beam splitter. To select the $\mathrm{OH}$-chem.-signal, a band-pass filter $(310 \mathrm{~nm})$ is used. Also a modular image intensifier is used because of the low signal intensity.

\section{Experimental procedure}

The behavior of the nozzles was analyzed at an operating point that is relevant for emission research. The engine speed is $n=1200 \mathrm{~min}^{-1}$, the center of heat release is $\mathrm{COHR}=367.5^{\circ} \mathrm{CA}$ and the indicated load of the high 
Table 3 Boundary conditions for the operating point

\begin{tabular}{lllllll}
\hline & $T_{\mathrm{CW}}\left({ }^{\circ} \mathrm{C}\right)$ & $T_{\mathrm{Oil}}\left({ }^{\circ} \mathrm{C}\right)$ & $T_{2}\left({ }^{\circ} \mathrm{C}\right)$ & $p_{2}$ (mbar) & $p_{3}$ (mbar) & $p_{\text {Rail }}$ (bar) \\
\hline Emission engine & 90 & 90 & 55 & 1690 & 1840 & 800 \\
Optical engine & 70 & 60 & 80 & 2050 & 2200 & 800 \\
\hline
\end{tabular}

Table 4 Calibration data of the injection system; $\mathrm{O}_{2}$ concentrations

\begin{tabular}{|c|c|c|c|c|c|c|}
\hline & \multirow[t]{2}{*}{ Engine } & \multicolumn{5}{|l|}{ Nozzle } \\
\hline & & $\mathrm{HF} 355 / 8 \mathrm{H}$ & $\mathrm{HF} 400 / 8 \mathrm{H}$ & HF355/14H & HF205/8H & $\mathrm{HF} 400 / 6+6 \mathrm{H}$ \\
\hline \multirow[t]{2}{*}{ SOE PI1 $\left({ }^{\circ} \mathrm{KW}\right)$} & Emission & 344.0 & 344.6 & 344.0 & 342.8 & 344.6 \\
\hline & Optical & 345.8 & 346.6 & 346.0 & 344.8 & 346.6 \\
\hline \multirow[t]{2}{*}{ ET PI1 $(\mu \mathrm{s})$} & Emission & 180 & 160 & 165 & 145 & 130 \\
\hline & Optical & 130 & 130 & 120 & 85 & 85 \\
\hline \multirow[t]{2}{*}{ SOE PI2 $\left({ }^{\circ} \mathrm{KW}\right)$} & Emission & 350.8 & 351.4 & 350.8 & 349.6 & 351.4 \\
\hline & Optical & 352.5 & 353.4 & 351.8 & 351.5 & 353.4 \\
\hline \multirow[t]{2}{*}{ ET PI2 $(\mu \mathrm{s})$} & Emission & 170 & 160 & 160 & 125 & 140 \\
\hline & Optical & 140 & 160 & 140 & 80 & 90 \\
\hline \multirow[t]{2}{*}{ SOE MI $\left({ }^{\circ} \mathrm{KW}\right)$} & Emission & 356.8 & 357.3 & 356.8 & 355.5 & 357.3 \\
\hline & Optical & 358.0 & 358.3 & 357.7 & 356.5 & 358.3 \\
\hline \multirow[t]{2}{*}{ ET MI $(\mu \mathrm{s})$} & Emission & 1000 & 850 & 1010 & 1550 & 800 \\
\hline & Optical & 900 & 800 & 950 & 1450 & 650 \\
\hline \multirow[t]{2}{*}{$\mathrm{O}_{2}\left(\mathrm{vol}^{2}\right)$} & Emission & 15.2 & 15.3 & 15.0 & 15.2 & 15.2 \\
\hline & Optical & & & & & \\
\hline
\end{tabular}

pressure cycle is $p_{\mathrm{mi}, \mathrm{HP}}=8.2$ bar. The boundary conditions of the operating point are shown in Table 3 for both engines.

The boost pressure of the optical engine was increased due to the lower compression ratio compared to the emission engine. The pressure level was set to achieve the same maximum compression pressure. The higher inlet temperature counteracts an increased fresh air mass caused by the increased inlet pressure. Furthermore, the cylinder walls and the injector are preheated while motoring the engine. Preheating is necessary because a continuous fired process is not possible due to blinding of the glass components. Hence, thermally stable conditions cannot be reached.

With the emission engine the exhaust gas recirculation (EGR) rate was set to achieve $\mathrm{NO}_{\mathrm{X}}$ raw emissions of $\mathrm{NO}_{\mathrm{X}, \mathrm{HP}}=0.6 \mathrm{~g} / \mathrm{kWh}$. With the optical engine the EGR is simulated by the injection of nitrogen. With that the oxygen concentration in the inlet manifold is regulated to the same levels that were measured for the emission engine. The values are set out in Table 4. The injection strategy includes two pre-injections (PI) and the main-injection (MI). The calibration data for the injection system is also shown in Table 4.

The injection rate of the used prototype injector shows a strong temperature dependency. Therefore, and because of the different nozzle flow rates, the start of energizing (SOE) and energizing time (ET) of the PIs were calibrated with the focus on similar heat release rates (HRR) for all nozzles (Fig. 2).

Due to the special characteristics of the optical engine in construction and operating, the SOE and ET had to be modified to achieve same load, COHR and similar HRRs as the emission engine. The lower thermal conductivity of the quartz glass and the higher intake temperature can lead to a reduced ignition delay. The mentioned characteristics of the prototype injector and the use of different engine control units lead to different ETs.

The optical engine is fired for 30 continuous cycles. The first 25 are only for the conditioning of the combustion chamber and the injector. For this there is only a single injection with low soot emission used. The last five cycles are fired with the specified injection pattern and were recorded with the camera system.

\section{Experimental results}

\subsection{Particulate matter emissions and fuel consumption}

Figure 2 illustrates the indicated fuel consumptions of the high pressure process $\left(\mathrm{bi}_{\mathrm{HP}}\right)$ and the heat release rates (HRR) measured on the emission engine. With all nozzles very similar fuel consumptions were measured. The values 
Fig. 2 Indicated fuel consumption and heat release rate
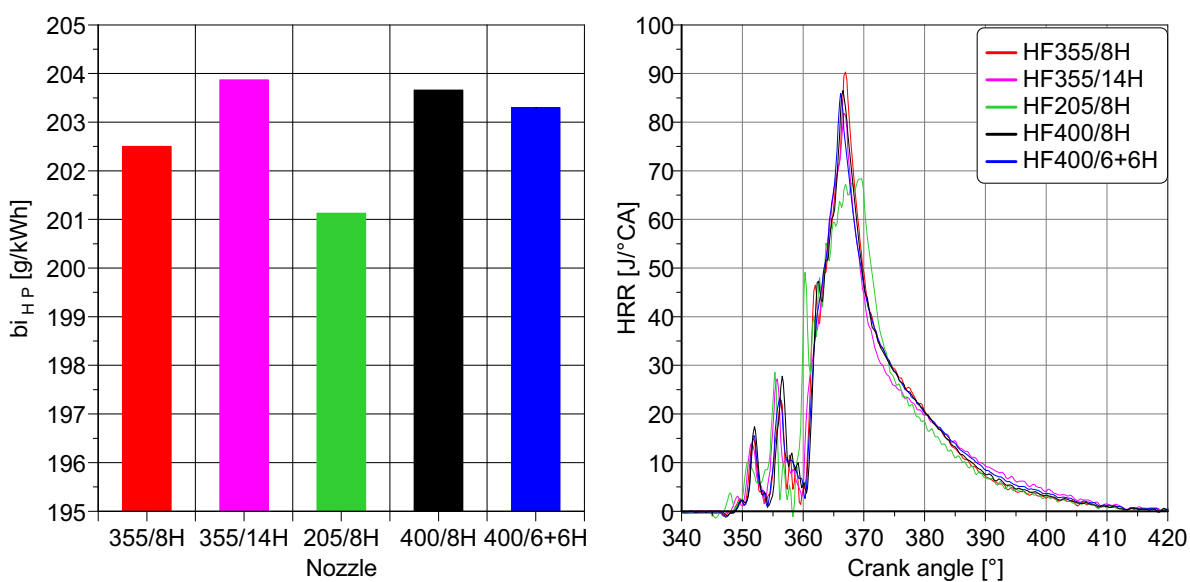

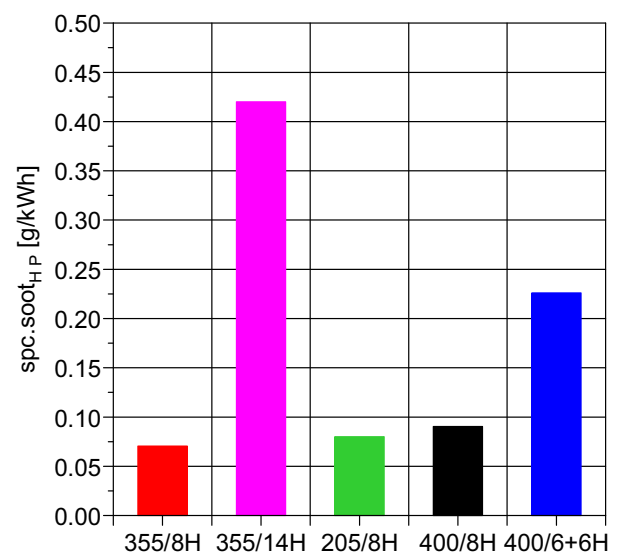

Fig. 3 Specific soot emissions

only differ by $2.6 \mathrm{~g} / \mathrm{kWh}$ in total while the HF205/8Hnozzle shows the lowest $(201.1 \mathrm{~g} / \mathrm{kWh})$ and the HF355/ 14H-nozzle the highest consumption $(203.9 \mathrm{~g} / \mathrm{kWh})$. The reasons for the differences can be seen in the HRRs in form of differing combustion durations and constant volume levels of the combustion. In addition the measured degrees of conversion show slight variances. But overall the deviations in the fuel consumptions nearly match the measurement uncertainty of $1 \%$.

In contrast, the PM emissions show significant differences which can be seen in Fig. 3. With the HF400/8Hnozzle that served as one of the references $0.09 \mathrm{~g} / \mathrm{kWh}$ was measured. With the second reference nozzle HF355/8H, PM emissions were slightly lower at $0.07 \mathrm{~g} / \mathrm{kWh}$. Decreasing the spray hole diameter from 130 to $120 \mu \mathrm{m}$ has positive effects on the soot-emissions. With the HF205/ $8 \mathrm{H}$-nozzle $0.08 \mathrm{~g} / \mathrm{kWh} \mathrm{PM}$ were emitted. So a further reduction of the spray hole diameter to $90 \mu \mathrm{m}$ with the same number of holes, leads to slightly higher PM emissions.

Increasing the number of holes with the HF355/14Hnozzle leads to a dramatic increase of the PM emissions.
With $0.42 \mathrm{~g} / \mathrm{kWh}$ they are six times the value of the reference. The 6+6-nozzle shows significantly higher PM emissions as well. With $0.23 \mathrm{~g} / \mathrm{kWh}$ they increase by a factor of 2.5 to its reference nozzle HF400/8H. Overall, the reduction of the soot emissions could not be achieved with the new spray hole configurations. The reasons for the significantly increased emissions were analyzed on the optical engine.

\subsection{Soot luminosity, OH-chemiluminescence and scattered-light}

In this section the results of the flame emission spectroscopy and those of the scattered-light method (SLM) are analyzed simultaneously. As an example, the first of the five fired cycles is shown. In one picture the soot luminosity ( $\mathrm{SoL})$ and the $\mathrm{OH}-$ chemiluminescence (OH-chem.) are superimposed and for better distinction they are displayed in false-colors. The SoL is colored red to yellow tones and the $\mathrm{OH}-\mathrm{chem}$. in blue tones. In addition, the records of the first and second PI made with the SLM are inserted into the image. It should be noted that the scattered-light images are from a different cycle due to the differing measurement setup. However, the penetration behavior of the liquid phase shows empirically, only relatively small fluctuations. In addition, note that the shape of the piston bowl leads to distortions in the image. The center of the combustion chamber is enlarged and the area around the center is partly compressed. This effect is more pronounced with increasing distance between the piston and the top dead center.

\subsubsection{Nozzle comparison HF355/8H-HF355/14H-HF205/ $8 H$}

At first, the HF355/8H-, HF355/14H- and HF205/8H-nozzle are compared at significant points of the cycle. The points marked in bold characters are shown in Figs. 4 and 
5. The first PI starts at $345^{\circ} \mathrm{CA}(\mathrm{HF} 205 / 8 \mathrm{H})$ and $346.2^{\circ} \mathrm{CA}(\mathrm{HF} 355 / 8 \mathrm{H}$ and HF355/14H), respectively, and is fully formed at $345.3^{\circ}$ and $346.5^{\circ} \mathrm{CA}$. As expected, the HF355/14H-nozzle shows a lower penetration depth than the HF355/8H-nozzle due to the smaller spray hole diameters. The recording of the HF205/8H-nozzle has in spite of the same spray hole diameters a higher penetration depth than the HF355/14H-nozzle. This can be due to the differing starting point of the injection and the resulting distortion in the picture.

The three nozzles show an ignition delay of $3.3^{\circ} \mathrm{CA}$. The maximum detected intensities of the flame emission were detected at $350.1^{\circ}$ and $348.9^{\circ} \mathrm{CA}$, respectively. Predominantly OH-chem. can be detected. Due to the long ignition delay, the air-fuel mixture can homogenize and the combustion is mostly premixed. On the images of the 8-hole-nozzles, the individual combustion zones can be seen, while with the 14-hole-nozzle a differentiation is not possible.

The second PI starts at around $352^{\circ} \mathrm{CA}(\mathrm{HF} 355 / 14 \mathrm{H}$, $\mathrm{HF} 205 / 8 \mathrm{H})$ and $352.8^{\circ} \mathrm{CA}(\mathrm{HF} 355 / 8 \mathrm{H})$, respectively. At $353.1(\mathrm{HF} 355 / 8 \mathrm{H})$ and $352.2^{\circ} \mathrm{CA}$ the penetration depth is at its maximum. The penetration behavior is similar to the first PI. At this time with the HF355/8H- and HF355/14Hnozzle the last reactions of the first PI take place, so that no significant ignition delay can be seen. With the HF205/8Hnozzle, the first pre-combustion is nearly completed because of a shorter ET and assumedly less injected fuel mass. So the second injection converts after an ignition delay of $1.5^{\circ} \mathrm{CA}$. Only $\mathrm{OH}$-chem. can be detected. With the HF355/14H-nozzle, OH-chem. predominates as well ( $\left.354^{\circ} \mathrm{CA}\right)$. Whereas with the HF355/8H-nozzle less OHchem. and more SoL can be seen at the same time after the beginning of the injection $\left(355.2^{\circ} \mathrm{CA}\right)$. This suggests a worse homogenization of the air-fuel mixture due to the larger spray holes. The second pre-combustion with the HF205/8H-nozzle, takes place almost as premixed combustion. So only $\mathrm{OH}$-chem. is detected. The first SoL is detected at $356.1^{\circ} \mathrm{CA}$. At this time with the HF355/8Hand the HF355/14H-nozzle there is widespread SoL. The ET of the HF205/8H-nozzle is shorter than for the other nozzles, so the injected fuel mass should be smaller although the HRRs of the seconds PIs are comparable. In combination with the small spray holes which provides a good homogenization of the air-fuel mixture, rich combustion zones rarely occur.

Corresponding to the lower hydraulic flow rate the MI with the HF205/8H-nozzle starts $1.5^{\circ}-1.8^{\circ} \mathrm{CA}$ earlier than the injections of the nozzles with the higher hydraulic flow. With all three nozzles, the MIs start while the combustion of the second PI is still taking place. So the fuel ignites without visible delay. At $361.8^{\circ} \mathrm{CA}$ the tips of the burning jets reach the wall of the piston bowl while the liquid

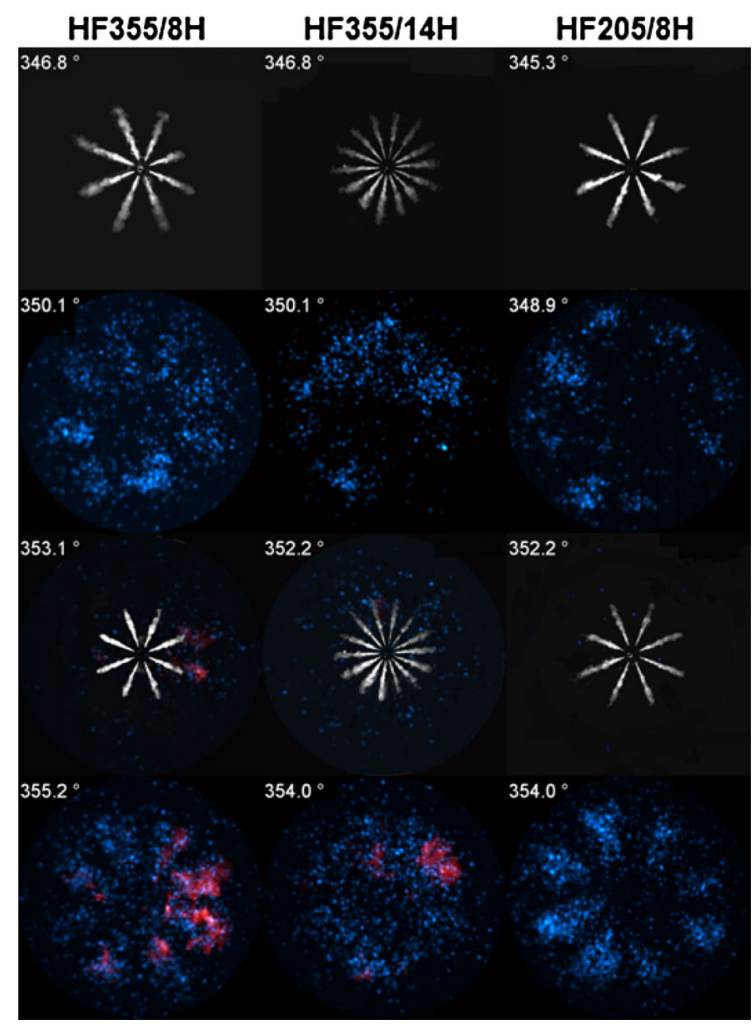

Fig. 4 SLM, OH-chem., SoL

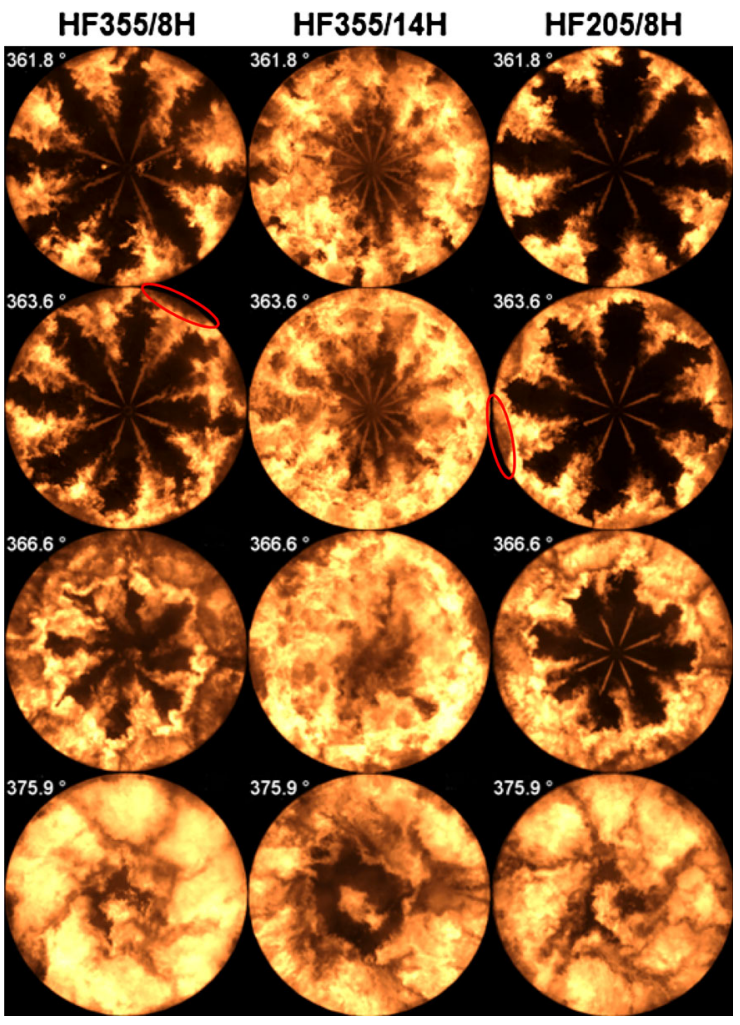

Fig. 5 Soot luminosity 
phases do not reach it with all nozzles. From here on the $\mathrm{OH}$-chem. is no longer shown because of the strong SoL. The 8h-nozzles show the vortices of the wall-jets which have progressed further in the clockwise direction according to the swirl-direction. With the 14h-nozzle hardly any wall-jets can be identified. Compared to the $\mathrm{HF} 355 / 8 \mathrm{H}$-nozzle the spray momentum is too small to create a distinct interaction with the wall. Although the spray hole diameters are equal to the HF205/8H-nozzle, the MI of the nozzle with the smaller hydraulic flow starts earlier. Therefore, more kinetic energy which appears in the same direction is generated with the injection process. Between the injection jets the 8h-nozzles show regions with unused air. The 14h-nozzle uses these regions more efficiently. But with that, the combustion zones partially overlap half way to the bowl wall. This may be a reason for the higher soot emissions of the 14h-nozzle, as very rich combustion zones may occur because fresh air entrainment is hardly possible.

The HF355/14H-nozzle does not even form clearly defined wall-jets at a later point in the combustion $\left(363.6^{\circ} \mathrm{CA}\right)$. The high number of spray holes leads to strong overlapping of the individual wall-jets so no directed flow can be achieved. This can lead to very rich combustion zones with high soot formation [6]. With both 8h-nozzles, the backflow to the center of the combustion chamber already occurs at this time. This is due to the momentum exchange and the deflection at the bowl wall and can be seen as dark clouds at the border (red markers). With the HF355/14H-nozzle a significant backflow can only be seen at $366.6^{\circ} \mathrm{CA}$, while with the 8 h-nozzles it is far advanced. At this time the injections of the nozzles with the hydraulic flow of $355 \mathrm{~cm}^{3} / 30 \mathrm{~s}$ just ended, while the HF205/8H-nozzle is still injecting. At $375.9^{\circ} \mathrm{CA}$ the backflow of the 8 h-nozzles covers almost the entire combustion chamber, whereas with the $14 \mathrm{H}$-nozzle there are still unused regions of air at the center.

\subsubsection{Nozzle comparison HF400/8H - HF400/6+6H}

Figures 6 and 7 shows images for the HF400/8H and HF400/6+6H-nozzles at significant points. The first PI starts with both nozzles at $346.8^{\circ} \mathrm{CA}$, at $347.7^{\circ} \mathrm{CA}$ the spray is fully formed. The HF400/8H-nozzle has a slightly unbalanced spray pattern, which might be due to needle seat throttling because of the short trigger time. The spray of the HF400/6+6H-nozzle shows first differences in the penetration as a result of the different spray hole diameters. For both nozzles the ignition delay is $3.6^{\circ} \mathrm{CA}$. The maximum intensities of the $\mathrm{OH}$-signal occur at $350.7^{\circ} \mathrm{CA}$ when the fuel is almost completely converted in a premixed combustion. Later slight SoL can be detected. The images of the 8h-nozzle show eight individual combustion zones,

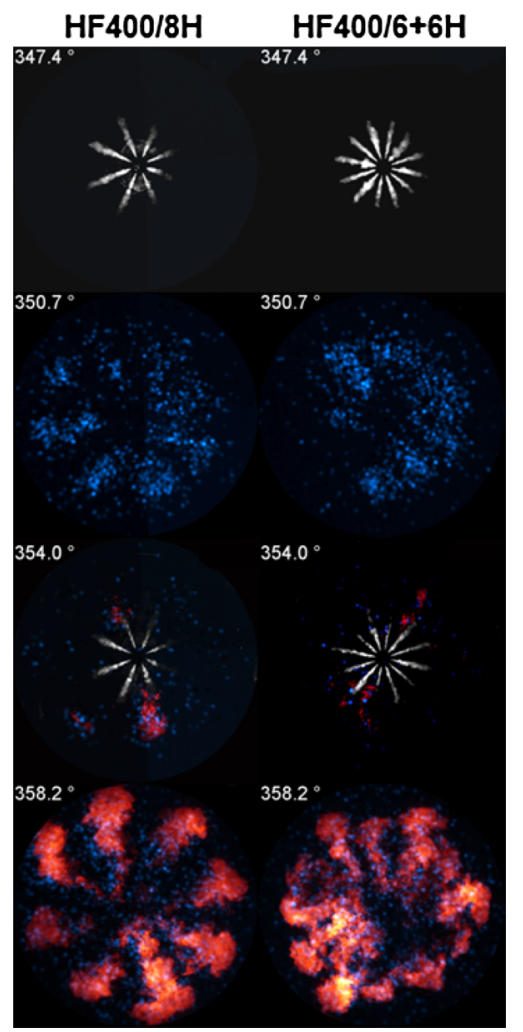

Fig. 6 SLM, OH-chem., SoL

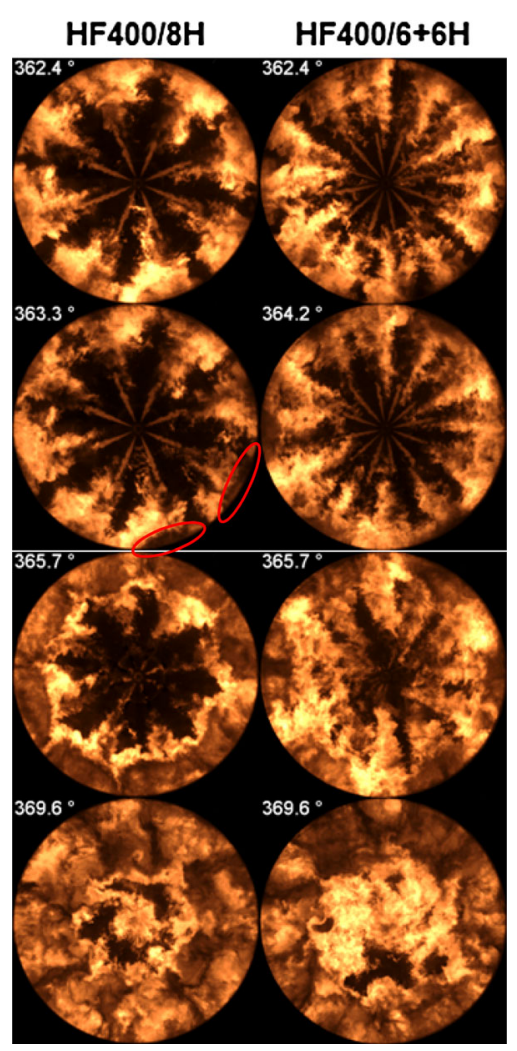

Fig. 7 Soot luminosity 
whereas with the 6+6-nozzle the zones cannot be distinguished.

The second PIs start at $353.4^{\circ} \mathrm{CA}$ while the last reactions of the first PIs is still taking place. At $354^{\circ} \mathrm{CA}$ the spray is fully formed and with that the differing penetration of the smaller and larger holes of the HF400/6+6H-nozzle can be observed even better than during the first PI. The fuel ignites without visible ignition delay. With both nozzles distinct SoL can be seen from the beginning. At $358.2^{\circ} \mathrm{CA}$ the SoL shows its maximum allocation. According to the number of spray holes, 8 or 12 combustion zones are visible. The images of the HF $400 / 6+6 \mathrm{H}-$ nozzle show slightly differing penetration depths due to the alternating hole diameters. In the centers of the burning jets both nozzles show strong SoL because there are rich combustion zones. At the borders $\mathrm{OH}$-chem. is detected due to the leaner air-fuel mixture.

The MIs start at $358.5^{\circ} \mathrm{CA}$ and ignite without visible delay. At $362.4^{\circ} \mathrm{CA}$ with both nozzles the wall-jets form at the bowl walls, while the injections are still taking place. The wall-jets of the $8 \mathrm{H}$-nozzle have further progressed in a clockwise direction. This effect is only partially visible with the HF400/6+6H-nozzle because the combustion zones are close together.

Contrary to the previously discussed HF355/14H-nozzle there is no strong overlapping of the individual combustion zones yet. So the decreased number of holes from 14 to 12 has probably improved the air entrainment into the spray. This and the reduced overlapping of the combustion zones are seen as the reason for the lower soot emission.

The recordings do not show significant differences between the penetration depth of the smaller and larger spray holes of the HF400/6+6H-nozzle. But compared to the HF400/8H-nozzle, the air in the middle of the combustion chamber is used better. The backflow with the HF400/8H-nozzle begins at $363.3^{\circ} \mathrm{CA}$ which can be seen as dark clouds at the border (red markers). With the HF400/ $6+6 \mathrm{H}$-nozzle, a significant backflow can first be seen at $364.2^{\circ} \mathrm{CA}$. At the end of the MI at $365.7^{\circ} \mathrm{CA}$ the backflow is formed around the entire bowl with the HF400/8Hnozzle. Corresponding to the number of holes there are eight darker areas. The HF400/6+6H-nozzle shows only six darker areas and the backflow does not include the entire circumference of the bowl. The momentum of the smaller spray holes seems to be too low to cause a significant backflow. The unused air in the middle regions with the HF400/8H-nozzle seems to be used better with the HF400/6+6H-nozzle due to the larger number of spray holes. The 6+6-nozzle finally causes a backflow around the entire circumference at $369.6^{\circ} \mathrm{CA}$. At this point, with the HF400/8H-nozzle the backflow already covers around twothird of the visible radius. With the HF400/6+6H-nozzle, the center of the combustion chamber is used, but only for the conversion of the low amount of fuel that was injected there due to the needle seat throttling, while closing the nozzle.

\subsection{Assessing the air utilization and the backflow}

Because the aim of the new nozzles is to improve the air utilization during the combustion process, this needs to be quantified. The images were evaluated pixel by pixel, and if a fixed threshold of the SoL-signal was exceeded, the pixel was rated as used. The number of used pixels was then summed up and averaged over the five recorded cycles. Figure 8 shows the values of the air utilization and the cumulative total for the analyzed nozzles.

All nozzles except for the HF205/8H reach a local maximum around $357^{\circ} \mathrm{CA}$. At this time the conversion of the second PI takes place. With the HF205/8H-nozzle the second PI is converted mostly in a premixed combustion so that rating the air utilization based on the SoL-signal is not possible.

The HF355/14H-nozzle and the HF400/6+6H-nozzle show the highest air utilization with 46 and $44 \%$. The HF355/8H-nozzle and the HF400/8H-nozzle achieve 39 and $38 \%$, respectively, due to the reduced number of spray holes. The subsequent increases of the air utilization are caused by the beginning of the main injection for all nozzles. In the interval from $359^{\circ}$ to $370^{\circ} \mathrm{CA}$, the aim of an improved air utilization is reached, especially with the HF355/14H-nozzle. The HF400/6+6H-nozzle shows an improvement in the air utilization compared to the reference (HF400/8H-nozzle). The advantages of the HF355/ $14 \mathrm{H}-$ and HF400/6+6H-nozzle are caused by the increased number of spray holes and the smaller penetration depth of the fuel, so that the middle areas of the combustion chamber are used too.

The increasing air utilization of the 8-hole-nozzles from $363^{\circ} \mathrm{CA}$, is due to the backflow of the combustion. The air utilization of the HF205/8H-nozzle is at the same level with the HF400/8H-nozzle for the time between $359^{\circ}$ and $370^{\circ} \mathrm{CA}$. No clear influence of the hydraulic flow is visible. As seen before, the backflow of the new nozzles is not as strongly developed as those of their references. This leads to worse air utilization from $370^{\circ} \mathrm{CA}(\mathrm{HF} 355 / 14 \mathrm{H})$ and $371^{\circ} \mathrm{CA}(\mathrm{HF} 400 / 6+6 \mathrm{H})$, respectively. The center of the combustion chamber is not used, while especially the HF355/8H-nozzle achieves a complete air utilization due to the backflow. Between $375^{\circ}$ and $380^{\circ} \mathrm{CA}$ the calculated air utilization is consistent with the soot emissions measured on the emission engine apart from the HF205/8H-nozzle. The images for the HF205/8H-nozzle also show high air utilization. But the fixed threshold there led to errors in the calculation. Very high soot concentrations extinguish the SoL. 
Fig. 8 Calculated air utilization

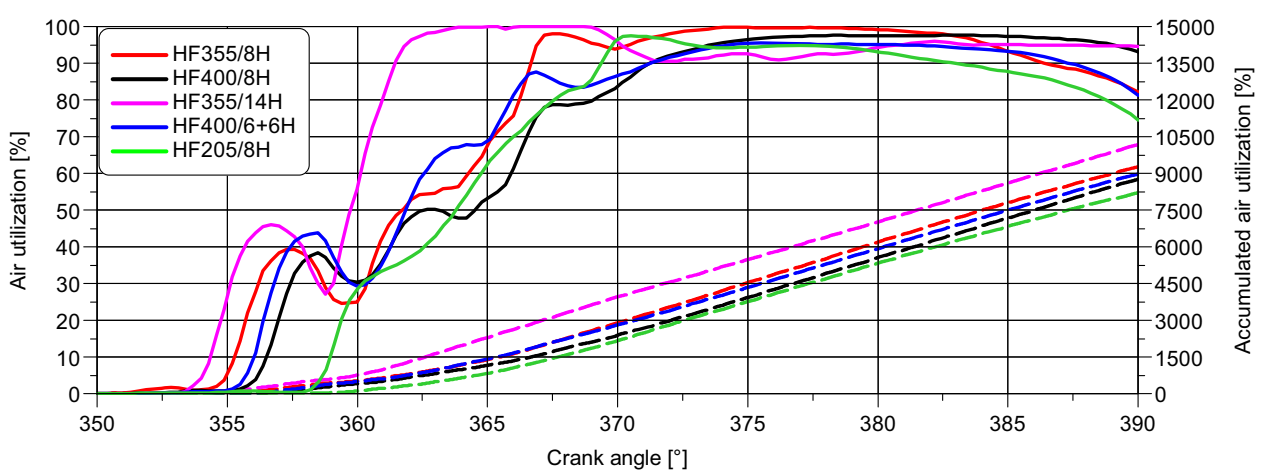

From $385^{\circ} \mathrm{CA}$ no further meaningful analysis is possible with the chosen method of calculation. The images show almost complete air utilization for all nozzles but the intensity of the SoL is below the threshold over wider areas.

Overall, it seems that the backflow of the combustion has a significant influence on the air utilization in the later stages of the main combustion and with that on the soot oxidation. To quantify this effect, a MATLAB based particle image velocimetry (PIV) program was used to calculate the flow velocities. This freely available program (PIV-Suite) was adjusted to detect patterns in the SoLimages and analyze their movements. The program uses the adaptive cross-correlation to compare two consecutive images. Here, only the radial velocity components were analyzed which are characteristic of the backflow. For each image, an average velocity was calculated and then averaged over the five recorded cycles.

Figure 9 shows the calculated velocities between $360^{\circ}$ and $380^{\circ} \mathrm{CA}$ when the backflow occurs. The absolute values of the velocities will not be discussed. The results are only used to compare the nozzles qualitatively. The differing velocities in the beginning result from the influences of the liquid spray and the second pre-combustion. The first significant increases in the calculated velocities correlate with the visible backflow in the recordings. Later, the velocity levels also agree with the measured soot emissions. The nozzles which cause the lowest soot emission (HF355/8H and HF205/8H) achieve the highest radial velocities. Compared to the HF205/8H, the HF355/14Hnozzle achieves lower velocities although they have the same spray holes diameter and probably the same spray momentums. Primarily, this is due to the longer injection time resulting from the lower hydraulic flow rate. With that, more kinetic energy is introduced locally by injection. It is also visible in the longer duration of the maximum velocity and when comparing the beginning of the backflow with the beginning and ending of the injection. With

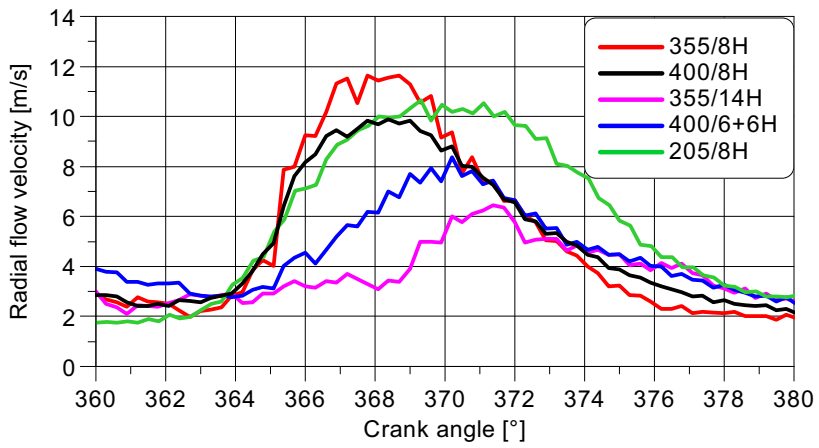

Fig. 9 Calculated radial velocities

the HF205/8H-nozzle the backflow starts at $362^{\circ} \mathrm{CA}$, which is $6.3^{\circ} \mathrm{CA}$ after the injection start. With the HF355/ $14 \mathrm{H}$-nozzle it begins $6.6^{\circ} \mathrm{CA}$ after the injection starts. So the distance is nearly the same and also the first increase of the velocity is similar. But with the HF355/14H-nozzle the injection already ends at $365.4^{\circ} \mathrm{CA}$ which corresponds with a short constant level in the graph. The injection of the HF205/8H-nozzle on the other hand continues till $368.4^{\circ} \mathrm{CA}$, which also approximately corresponds with the maximum of the flow velocity.

The HF400/8H- and the HF400/6+6H-nozzle have the same injection beginnings and durations. In spite of this, the backflow of the HF400/6+6H-nozzle occurs $1.2^{\circ} \mathrm{CA}$ later. It is supposed that the jets of the small spray holes impede the wall-jets of the larger holes because of interaction. But the wall-jets enhance the air utilization and the backflow towards the center of the combustion chamber [6]. The gradient of the velocity of the HF400/6+6Hnozzle is lower than the gradient of the HF400/8H-nozzle. With the 6+6-nozzle the backflow first occurs only in the areas of the larger spray holes so a lower average value for the velocity is calculated. At around $370^{\circ} \mathrm{CA}$ both nozzles show a similar velocity level. At this point the HF400/ $6+6 \mathrm{H}$-nozzle also forms a backflow that covers the entire bowl circumference. 


\section{Summary and conclusion}

The aim of this investigation was the reduction of the soot emissions by an improved utilization of the air between the injection jets. For this five different nozzles were analyzed at a part load point with $n=1200 \mathrm{~min}^{-1}$ and $p_{\text {mi,HP }}=8.2$ bar. Based on an 8-hole reference-nozzle and a hydraulic flow of $355 \mathrm{~cm}^{3} / 30 \mathrm{~s}$, the number of holes was increased to 14 with suitable smaller spray hole diameters. Moreover, an innovative 6+6-nozzle with differing spray hole diameters and a hydraulic flow of $400 \mathrm{~cm}^{3} / 30 \mathrm{~s}$ was analyzed. This nozzle is provided with six larger and six smaller holes, which are alternating on the same hole circle. The reference here is an $8 \mathrm{~h}$-nozzle with the same flow rate. To examine the impact of reduced spray hole diameters independent from the number of holes, an $8 \mathrm{H}$-nozzle with a hydraulic flow of $205 \mathrm{~cm}^{3} / 30 \mathrm{~s}$ was analyzed. The spray hole diameters here are the same as those of the 14- and the smaller ones of the 6+6-nozzle.

The investigations have shown that an increased numbers of spray holes in combination with smaller spray hole diameters can improve the air utilization at the beginning of the main combustion. But in the later stages of the combustion the air utilization is worse. Due to the reduced spray momentum there is no such distinct backflow of the combustion from the bowl wall towards the center. Consequently, there remain unused regions of air which should have negative effects on the soot oxidation. In addition, if the spray hole number is too high, the individual burning jets can overlap which leads to very rich combustion zones with high soot building potential.

A long injection duration can have positive effects on the air utilization in the burnout phase of the combustion. Thus, even with small spray hole diameters and a small spray momentum a distinct backflow towards the center of the combustion can be reached. The sum of kinetic energy, which appears in the same direction, is higher. The part of the injection with needle seat throttling, which reduces the spray momentum, decreases.

The potential of the nozzles regarding the soot emissions and the fuel consumption was analyzed on a single cylinder research engine. Afterwards the nozzles were measured on an optical engine. The combustion was analyzed by soot luminosity and $\mathrm{OH}$-chemiluminescence. Furthermore, the liquid spray was visualized with the scattered-light method.

The measured fuel consumptions are all between $\mathrm{bi}_{\mathrm{HP}}=201.1 \mathrm{~g} / \mathrm{kWh} \quad(\mathrm{HF} 205 / 8 \mathrm{H})$ and $\mathrm{bi}_{\mathrm{HP}}=203.9 \mathrm{~g} /$ $\mathrm{kWh}(\mathrm{HF} 355 / 14 \mathrm{H})$. The differences can be explained partly by differing degrees of conversion and the combustion duration. But with a measurement inaccuracy of
$1 \%$ these differences are not significant. The soot emissions on the other hand show clear differences. The HF355/ $14 \mathrm{H}$-nozzle shows $0.42 \mathrm{~g} / \mathrm{kWh}$, which is five times the value of the reference. At the beginning of the main injection, the unused air in the middle region of the combustion chamber is used better, but the burning zones are very close to each other, so nearly no air entrainment is possible. In addition, the burning zones overlap near the wall of the piston bowl which results in very rich combustion zones with high soot formation potential. The HF400/6+6H-nozzle with $0.23 \mathrm{~g} / \mathrm{kWh}$ has 2.5 times the soot emissions of its reference $(\mathrm{HF} 400 / 8 \mathrm{H})$. With this nozzle, the air utilization at the beginning of the main combustion is improved too. The individual combustion zones show sufficient distances between each other so that air entrainment in the spray is possible. In addition, there is no such strong overlapping of the burning jets at the bowl wall. Both result in lower soot emissions compared to the HF355/14H-nozzle.

Furthermore, it was found that the interaction of the combustion with the bowl wall is an important influence factor for the air utilization in the later stages of the combustion process. The reference nozzles with eight spray holes show a significant backflow towards the center of the combustion chamber due to the deflection on the bowl wall and the vortices of the wall-jets in circumference direction. To quantify the backflow, the radial flow velocities were calculated with a PIV-program based on the SoL-images. The nozzles that show the highest flow velocities have the lowest soot emissions. With the 14h-nozzle the backflow only starts at a very late stage of the combustion and with a low velocity level. The spray momentum seemed to be too small due to the small spray holes. With that, the air utilization in the burnout phase is worse due to unused regions of air at the center of the combustion chamber. The HF205/ $8 \mathrm{H}$-nozzle that has the same spray hole diameters achieves high velocities and low soot emissions. This is a result of the long injection time that introduces more kinetic energy, which appears in the same direction. Furthermore, with the long duration, the part of the injection with needle seat throttling, which reduces the spray momentum, decreases. The backflow with the HF400/6+6H-nozzle is also less developed than that of its reference, which results in a worse air utilization during the burnout phase. But the flow velocities are higher than those of the HF355/14H-nozzle. The larger spray holes of the 6+6-nozzle generate sufficient momentum to achieve a reflection on the bowl wall. But the backflow starts later than that of its reference. It is conjectured that the jets of the smaller holes with their low penetration depth impede the forming wall-jets of the larger spray holes and the backflow of the combustion. 


\section{References}

1. Schubiger, A.: Untersuchungen zur Russbildung und -oxidation in der dieselmotorischen Verbrennung, Thermodynamische Kenngrössen, Verbrennungsanalyse und Mehrfarbenendoskopie. Dissertation ETH Zürich Nr. 14445 (2001)

2. Ishiwata, H., Li, X., Yoshikawa, H., Kitahara, N., Recent Progress in Rate Shaping Technology for Diesel In-Line Pumps. SAE Technical Paper 940194 (1994)

3. Gao, J., Matsumoto, Y., Namba, M., Nishida, K.: Group-Hole Nozzle Effects on Mixture Formation and In-cylinder Combustion Processes in Direct-Injection Diesel Engines. SAE 2007-014050

4. Leipertz, A., Blumenröder, K., Schünemann, E., Peter, F., Potz, D.: Wandeinflüsse auf Gemischbildung und Verbrennung bei kleinvolumigen DI-Dieselmotoren, Teil 2: Grundlagenuntersuchungen. MTZ 60 (1999)

5. Pauer, T.: Laseroptische Kammeruntersuchungen zur dieselmotorischen Hochdruckeinspritzung-Wirkkettenanalyse der Gemischbildung und Entflammung. Dissertation Universität Stuttgart (2001)

6. Leipertz, A., Blumenröder, K., Schünemann, E., Peter, F., Potz, D.: Wandeinflüsse auf Gemischbildung und Verbrennung bei kleinvolumigen DI-Dieselmotoren, Teil 1: Motorische Untersuchungen. MTZ 60, vol. 5, pp. 314-319 (1999)

7. Hübner, M., Koch, P., Zellbeck, H., Leipertz, A., Kerst, A.: Wirkkettenanalyse der dieselmotorischen Verbrennung, Einfluss von Brennraumwand und Kraftstoff. MTZ 04/2008 vol. 69, pp. $342-350$

8. Schulze, T.: Untersuchung des Einflusses der Spritzlochgeometrie der Einspritzdüsen auf die dieselmotorische Gemischbildung und Verbrennung. Dissertation Technische Universität Dresden (2005)

9. Schneider, B.M.: Experimentelle Untersuchungen zur Spraystruktur in transienten, verdampfenden und nicht verdampfenden Brennstoffstrahlen unter Hochdruck. Dissertation ETA Zürich Nr. 15004 (2003)

10. Bowditch, F.W.: A new tool for combustion research, a quarz piston. SAE 610002

11. Mie, G.: Beiträge zur Optik trüber Medien, speziell kolloider Metallösungen. Annalen der Physik, Band vol. 25, pp. 377-445 (1908)

12. Raffel, M., Willert, C., Wereley, S., Kompenhans, J.: Particle Image Velocimetry, A Practical Guide. Springer, Heidelberg (2007)

13. Planck, M.: Ueber das Gesetz der Energieverteilung im Normalspectrum. WILEY-VCH, Weinheim (1901)

14. Henle, A.: Entkopplung von Gemischbildung und Verbrennung bei einem Dieselmotor. Dissertation Technische Universität München (2006)

15. Pittermann, R.: Spektroskopische Untersuchung der Verbrennung in Diesel- und Gasmotoren. MTZ 07-08/2008

16. Gaydon, A.G.: The Spectroscopy of flames. Chapman and Hall, London (1974) 